\title{
РОССИЙСКАЯ И ЗАРУБЕЖНАЯ ПРАКТИКА ГОСУДАРСТВЕННО-ЧАСТНОГО ПАРТНЕРСТВА В УСЛОВИЯХ ТРАНСФОРМАЦИИ ЭКОНОМИКИ'
}

\section{RUSSIAN AND FOREIGN PRACTICE OF PUBLIC-PRIVATE PARTNERSHIP IN THE CONTEXT OF ECONOMIC TRANSFORMATION}

\section{Androsova \\ O. Nepochatykh O. Lebedenko}

Summary. The article substantiates the application of the mechanism of public-private partnership within the framework of economic and legal methods of state regulation. The authors reviewed the Russian and foreign experience in the application of public-private partnership at the present stage of development; identified the leading countries; studied the measures of state support in Russia and a number of foreign countries. The article uses modern digital material that allows an adequate assessment of the volume of investment in public-private partnership projects. The authors conduct a comparative analysis of the Russian and foreign practice of public-private partnership according to the previously identified criteria. The study of the Russian and foreign practice of public-private partnership allowed the authors to formulate modern trends in its development and the main tools and technologies that ensure their implementation.

Keywords: public-private partnership; government regulation; infrastructure development; transformation; PPP projects; integration; digital platforms; transformation of the economy.

\section{Введение}

A ктуальность исследования определена тем, что использование инструментов государственно-частного партнерства (ГЧП) в условиях трансформации экономики позволит не только определить экономические сдвиги при реализации взаимовыгодных проектов, но и в перспективе повысить уровень
Андросова Ирина Владимировна

К.э.н., дочент, Юго-Западный государственный университет

irinka-rusik@mail.ru

Непочатых Ольга Юрьевна

К.э.н., доцент, Курский филиал Финансового университета при Правительстве Российской

Федерации

holga1306@yandex.ru

Лебеденко Ольга Сергеевна

М.н.С., Юго-Западный государственный университет

olgalebedenko22@gmail.ru

Аннотация. В статье обосновано применение механизма государственно-частного партнерства в рамках экономических и правовых методов государственного регулирования. Авторами рассмотрен российский и зарубежный опыт применения государственно-частного партнерства на современном этапе развития; выделены страны - лидеры; изучены меры государственной поддержки в России и ряде зарубежных стран. В статье использован современный цифровой материал, позволяющий дать адекватную оценку объемам инвестирования в проекты государственно-частного партнерства. Авторы проводят сравнительный анализ российской и зарубежной практики государственно-частного партнерства по выделенным ранее критериям. Изучение российской и зарубежной практики государственно-частного партнерства позволило авторами сформулировать современные тренды его развития и основные инструменты и технологии, обеспечивающие их реализацию.

Ключевые слова: государственно-частное партнерство; государственное регулирование; инфраструктурное развитие; трансформация; ГЧП-проекты; интеграция; цифровые платформы; трансформация экономики.

и качество социальной сферы. Интеграция государства и бизнеса является важнейшим аспектом в развитии страны $[9,11]$.

Положительные эффекты, которые можно выделить на начальном этапе сотрудничества, определяют дальнейшие тенденции и перспективы в рамках инновационного и инвестиционного развития как отдельных 


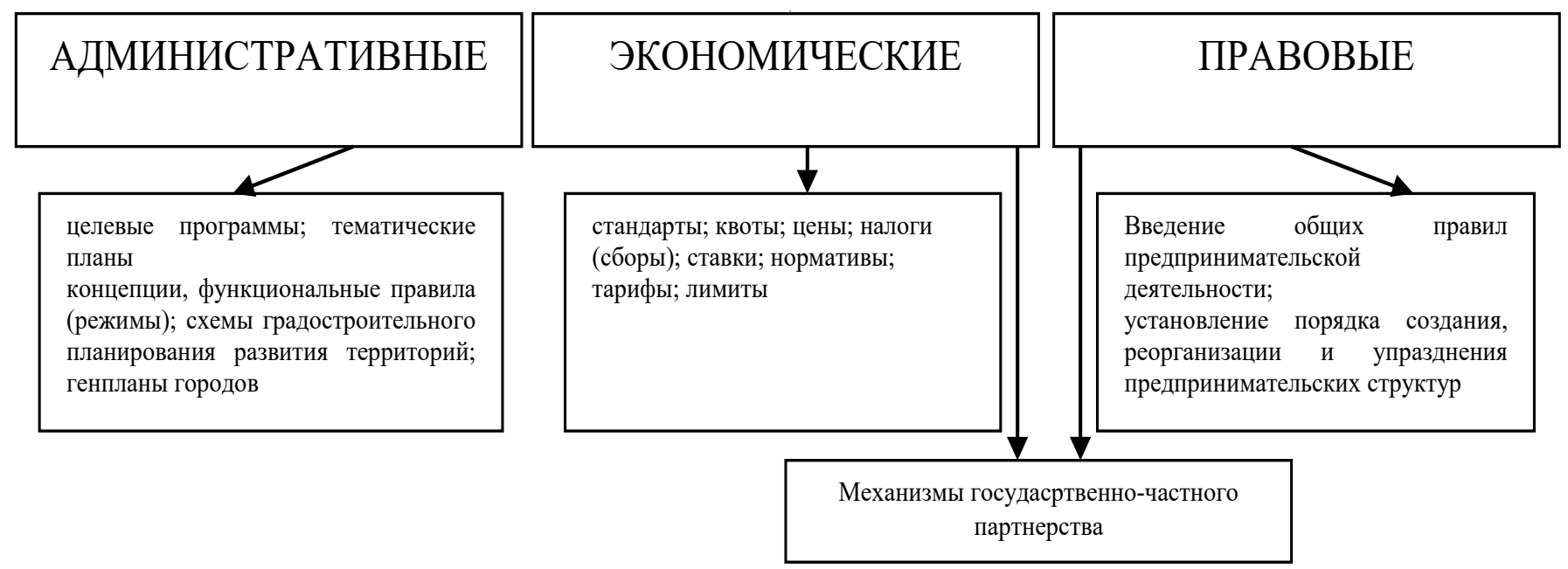

Рис. 1. Систематизация методов государственного регулирования экономики Источник: составлено авторами по материалам [2; 3; 5; 7].

регионов, так и бизнеса. Улучшается состояние социально-культурной инфраструктуры. В современных условиях, в период вызовов внешней среды, дестабилизации макроэкономических условий из-за пандемии необходимо решить проблему поддержки бизнеса с минимальными затратами и эффективным использованием инфраструктурных ресурсов для обеспечения долгосрочного сотрудничества в деятельности государства и предпринимательских структур [2].

При этом очень важно учесть баланс интересов и государства, и бизнеса. Финансовая поддержка - самый распространенный способ государственного стимулирования. В связи с этим требуется усиление контроля за денежными потоками, за исполнение договорных обязательств. Но это приводит к увеличению бюджетной нагрузки, возникают условия, при которых требуется пересмотреть условия налогообложения. При этом нужно учитывать, что поддержка в виде государственных гарантий тоже необходимое условие. Изучение российской и зарубежной практики государственно-частного партнерства позволит выявить основные тенденции и создать наиболее совершенную модель взаимовыгодного сотрудничества в условиях трансформации экономики.

\section{Материалы и метоны}

При написании статьи использованы общенаучные и специальные методы: монографический; абстрактно-логический; сравнительного анализа. Эмпирической базой исследования послужили данные аналитических обзоров рынка инфраструктурного развития; публично доступной информации, а также разработок авторов, полученных в ходе исследования.

\section{Результаты и их обсужАение}

Для нормального функционирования и развития общества на макроэкономическом уровне необходимо активное участие государства. Огромное значение имеют используемые методы государственного воздействия на основные макроэкономические показатели: темпы роста ВВП, процессы инфляции и безработицы, а также уровень развития инфраструктуры, обеспечивающей условия для эффективного развития экономики. Невозможно подобрать универсальную методологию, адаптированную для всех условий. В связи с этим правомерным представляется подход к выбору методов, основанный на оценке имеющихся условий и факторов развития. Для осуществления государственной политики используют различные методы, традиционно подразделяющиеся на правовые, административные, экономические (рис. 1).

В основе данной систематизации лежит общепринятая классификация методов государственного регулирования на правовые, административные и экономические. Показатели эффективности государственной поддержки определяются методами сопоставления интересов государства и бизнеса. В рамках административных методов для поддержания уровня предпринимательской деятельности и ее стимулирования выделяются формирование нормативно-правовых условий для развития бизнеса, совершенствование системы отношений «государство - бизнес», развитие инфраструктуры, оказание информационно-консультационной поддержки. Примерами на российской практике могут служить снижение надзорной нагрузки, послабления в лицензировании и иных разрешительных процедурах. 
В Японии постоянное внимание уделяется именно географическому положению малого и среднего предпринимательства для развития экономики отдельных регионов и содействия сотрудничеству между предприятиями одной сферы деятельности. Власти Китая заботятся о подготовке кадров различных категорий для поддержки бизнеса. К группе правовых методов относят мораторий на банкротство, освобождение от весового контроля транспортных средств, перевозящих товары первой необходимости, смягчение миграционного законодательства и др. Одним из моментов стимулирования развития бизнеса в российском законодательстве является упрощенная регистрация предпринимателя в статусе самозанятый.

В США активно поддерживаются программы создания «зон предпринимательства», имеющих особые правовые условия в рамках предоставления и оформления документации. Экономические методы представлены по большей мере в виде финансовой поддержки предпринимательства: особый режим налоговой и ценовая политики для социально значимого бизнеса, распределение государственных инвестиций на основе конкурсного отбора проектов, прямое финансирование на долгосрочной основе [8].

Также хотелось бы отметить, что кроме способов поддержки предпринимательской деятельности, существуют еще и «запрещающие» способы регулирования бизнеса: санкции в виде штрафов, контроль и учет за совершением сделок, качеством выполненных работ, проверки и иные формы контроля. Это тоже является мерой стимулирования бизнеса. Согласно практике EC, если предпринимательская деятельность была разрешена в одной стране ЕС, дальнейшее разрешение не требуется в другом государстве-члене, т.к. представители бизнеса уже прошли процедуру проверки [12].

Однако на практике меры государственного регулирования могут сочетать в себе одновременно признаки различных методов. К одному из смешанных методов регулирования можно отнести государственно-частное партнерство (ГЧП), подразумевающее под собой юридическую основу (проявление правовых методов) взаимодействия между государственными и частными структурами для реализации общественно значимых проектов (проявление экономических методов) с учетом соблюдения баланса обоюдных интересов.

Правовые аспекты методов регулирования проявляются в том, что в российском законодательстве предусмотрены различные организационно - правовые формы государственно-частного партнерства. В российской практике государственно-частное партнерство реализуется преимущественно в формах кон- цессионного соглашения и соглашениях о ГЧП, отличающихся по принадлежности обслуживаемого объекта к частной или государственной собственности. Среди других организационно-правовых форм (квази - ГЧП) в российской практике применяются контракт жизненного цикла, инвестиционный договор (контракт), энергосервисный контракт, корпоративная форма партнерства.

В зарубежной практике государственно-частные партнерства активно реализуются в форме концессий (США, Бразилия), контракты (Великобритания, Франция), аренда (Германия), соглашения о разделе продукции (Египет, Индонезия), совместные предприятия (Япония, Китай). Стоит еще отметить и состояние нормативно-правовой базы ГЧП в мировой практике. Так в ряде стран (Германия, Польша, Румыния, Япония, Россия и другие) приняты специальные законы о ГЧП. В других же странах (Италия, Великобритания, Китай и другие) действуют законодательные акты, закрепляющие основные принципы ГЧП. Кроме того, на текущий момент времени существует группа государств, в которых ГЧП законодательно не урегулирован (Австрия, Швеция, Эстония и другие).

Элементы экономических методов, присущих государственно-частному партнерству, проявляются в удовлетворении взаимных интересов государственных и частных структур. Выгода при реализации проектов ГЧП для государства заключается в использовании ресурсов и компетенций частных структур, а для бизнеса - возможность расширения новых рынков сбыта, что приводит к росту доходов. Средне - и долгосрочный характер реализации позволяет отделить ГЧП от таких форм взаимодействия государства и бизнеса как государственные заказы и закупки, осуществляемые в течение краткосрочного периода. В основе механизма ГЧП лежит объединение ресурсов и компетенций участников (государство и бизнес) для реализации капиталоемких инфраструктурных проектов в различных отраслях экономики [6].

В 2021 году, по данным информационного агентства Росинфра [4], в России ГЧП-проекты реализовывались преимущественно в транспортной, социальной, топливно-энергетической и иных сферах. По количеству проектов лидирует коммунально-энергетическая (2678 ед.), а по объему инвестиций - транспортная сфера (2807 млрд. руб.). Территориальное распределение ГЧП-проектов в 2021 году свидетельствует о лидерстве Приволжского и Центрального федеральных округов по количеству и объему инвестиций. В меньшей степени механизмы ГЧП востребованы в Северо-Кавказском федеральном округе (0,3\% совокупного объема инвестиций и $1 \%$ портфеля проектов). 
Из общего объема проектов $81 \%$ реализован в форме концессионных соглашений, менее $20 \%$ проектов приходится на различные формы квази- ГЧП (энергосервисные контракты, договоры аренды с инвестиционными обязательствами). Основная часть ГЧП-проектов в 2021 году (90\%) реализуется на муниципальном уровне (22 проекта на сумму 28 млрд. руб.), а на региональном и федеральном уровнях осуществляются наиболее капиталоемкие проекты в сфере транспортной и социальной инфраструктуры (15 проектов на сумму 51 млрд. руб.) [4].

Зарубежная практика использования механизмов ГЧП свидетельствует о наиболее успешной реализации проектов в Великобритании, США, Франции, Италии, Германии, Японии. Традиционно считается, Великобритания родиной государственно-частного партнерства, которая использовала данный механизм еще в 1981 году при перестройке лондонских доков. А в 1992 году был принят курс на новую концепцию управления государственной собственности - Частную финансовую инициативу, заключающуюся в передаче бизнесу функций по финансированию государственных инфраструктурных объектов. К проектам начального периода государственно-частного партнерства относятся общественная библиотека в г. Борнмун, школы в Бриджпорте и Дорсете, здания полиции в Илкестоне, северного кольца Бирмингема и железнодорожной сети Кройдона.

На современном этапе развития в Великобритании действует Программа приоритетного строительства 537 школ, из которых 260 - восстановлено за счет бюджетных средств (214) и частных финансов (46). В оставшихся 277 школах основное внимание уделено отдельным блокам, которые будут восстановлены к концу 2021 года за счет гранта на капитальный ремонт. Объем финансирования Программы составил 4,4 млрд. фунтов стерлингов [4]. В немецкой практике проекты ГЧП первоначально реализовывались в кооперативном строительстве. Одним из успешных проектов считается реконструкция крупнейшего аэропорта в Германии во Франкфурте.

В настоящее время на условиях ГЧП ведутся работы по строительству нового пассажирского терминала, однако срок ввода в эксплуатацию зависит от факторов внешней среды. Во Франции четко прослеживаются традиции государственно - частного партнерства на принципах концессии. Примерами реализации ГЧП - проектов являются строительство евротоннеля, соединяющего Англию и Францию под проливом ЛаМанш, Эйфелева башня в Париже. В настоящее время проекты реализовываются в строительной и социальной сферах. Результаты изучения опыта ведущих стран в области ГЧП позволили сделать вывод о том, что партнерства используются в транспортной, социальной, ЖКХ и других отраслях, но несомненными лидерами являются транспортная и социальная инфраструктура.

Обобщение российской и зарубежной практики применения государственно-частного партнерства представлено в таблице 1. Сравнительный анализ российской и зарубежной практики государственно-частного партнерства показывает, что не во всех представленных странах сформирована законодательная база ГЧП. Состав приоритетных сфер, где чаще всего реализуются механизмы ГЧП, дают основания полагать, что усилия сконцентрированы в транспортной, социальной сферах, а также в ЖКХ. Представленные данные свидетельствуют также об инновационной направленности ГЧП-проектов в различных странах.

Влияние пандемии коронавируса на мировой рынок капитальных инвестиций проявилось, прежде всего, в резком снижении спроса на объекты инфраструктуры (за исключением объектов здравоохранения), что и привело к приостановке запуска ряда крупных объектов. Все это обусловило падение рынка инфраструктурных ГЧП-проектов в различных странах. Совокупная стоимость сделок по ГЧП - проектам на европейском рынке сократилась практически на 30\% в 2020 году по отношению к 2019 году с 10,8 млрд. евро до 7,9 млрд. евро, при этом было завершено всего лишь 34 проекта. В развивающихся странах расходы на ГЧП-проекты снизились вполовину в 2020 году по сравнению с 2019 годом. Резкое сокращение (в 4 раза) инвестиций в ГЧП-проекты сильно прослеживается в странах Азиатско-Тихоокеанского региона. При этом в странах Южной Азии объем рынка сократился только на 17\%, а в странах Африки и Ближнего Востока объем инвестиций в ГЧП-проекты увеличился с 0,8 млрд. долл. в 2019 году до 1,2 млрд. долл. в 2020 году [4].

В условиях пандемии стимулирование развития экономики в различных регионах мира невозможно без мер государственной поддержки. Так, в США в июле 2021 года предложен «План Байдена», согласно которому планируется восстановить ключевые объекты транспортной и социальной инфраструктуры. В Китае в рамках 14-го пятилетнего плана инфраструктурные объекты становятся одним из важнейших направлений. В Германии и Италии ключевым объектом является модернизация железнодорожной инфраструктуры.

В Германии финансирование планируется частично за счет средств немецкой компании Deutsche Bahn в размере 12,7 млрд. евро., а в Италии за счет национального железнодорожного оператора Ferrovie dello Stato - 58 млрд. евро. В Австралии правительство 
Таблица 1. Сравнение российской и зарубежной практики государственно-частного партнерства

\begin{tabular}{|c|c|c|c|}
\hline Страна & $\begin{array}{l}\text { Законодательная база } \\
\text { на федеральном уровне }\end{array}$ & $\begin{array}{l}\text { Приоритетные сферы } \\
\text { ГЧП }\end{array}$ & $\begin{array}{l}\text { Использование механизмов развития } \\
\text { инновационной деятельности в проектах } \\
\text { ГЧП }\end{array}$ \\
\hline Великобритания & Отсутствует & $\begin{array}{l}\text { Образование, } \\
\text { здравоохранение }\end{array}$ & \begin{tabular}{|l} 
Подготовка концессионных проектов ГЧП \\
(инновационная деятельность в приоритете)
\end{tabular} \\
\hline Франция & $\begin{array}{l}\text { Закон «О контрактах ГЧП», } \\
2008 \text { г. }\end{array}$ & Строительство, ЖКХ & Инвестиционные фонды \\
\hline Италия & Отсутствует & $\begin{array}{l}\text { Транспорт, } \\
\text { здравоохранение }\end{array}$ & Венчурные инвестиции \\
\hline Германия & Закон «О развитии ГЧП», 2005 г. & $\begin{array}{l}\text { Образование, } \\
\text { здравоохранение, } \\
\text { транспорт }\end{array}$ & $\begin{array}{l}\text { Введение } \\
\text { особого налогового и таможенного режима } \\
\text { на федеральном и региональном уровнях }\end{array}$ \\
\hline США & Отсутствует & $\begin{array}{l}\text { Образование, } \\
\text { здравоохранение, } \\
\text { транспорт }\end{array}$ & $\begin{array}{l}\text { Особое место занимают методы проектного } \\
\text { и облигационного инвестирования } \\
\text { для стимулирования инновационной } \\
\text { деятельности } \\
\end{array}$ \\
\hline Япония & Отсутствует & $\begin{array}{l}\text { Здравоохранение, ЖКХ, } \\
\text { транспорт, ИТ }\end{array}$ & $\begin{array}{l}\text { Совершенствование системы особого } \\
\text { взаимодействия государства, бизнеса } \\
\text { и науки. Трансферт технологий } \\
\end{array}$ \\
\hline Китай & Отсутствует & $\begin{array}{l}\text { Транспорт, Образование, } \\
\text { здравоохранение }\end{array}$ & Инструменты поддержки экспорта \\
\hline Россия & Закон «О ГЧП, МЧП», 2015 г. & $\begin{array}{l}\text { Транспорт, образование, } \\
\text { здравоохранение }\end{array}$ & Формирование инновационных кластеров \\
\hline
\end{tabular}

Составлено авторами по материалам $[1 ; 10 ; 12 ; 13]$.

учредило Фонд содействия восстановлению после COVID-19 с бюджетом в A\$1 млрд., часть которых будет направлена на восстановление авиапромышленных объектов как наиболее пострадавших в период пандемии. В Турции стартовала государственная инвестиционная программа на 2021 год на сумму 18,5 млрд. долл., которые будут направлены на поддержку транспортного и IT-сектора, а также образовательных проектов [4]. Правительство Бразилии к концу 2021 года планирует выставить на аукцион 100 проектов, реализуемых на основе концессионных соглашений.

В России перечень мер поддержки проектов, реализуемых на принципах ГЧП, в 2020-2021 гг. расширился и стал охватывать все основные отрасли инфраструктуры. Среди новых способов поддержки ГЧП, реализуемых в 2021 году, выделяются следующие:

- создание инфраструктурного меню, ориентированного на выдачу бюджетных кредитов, направляемых на развитие транспортной, социальной и общегородской инфраструктуры регионов;

- запуск масштабной программы по созданию новых школ. Координатором реализации проекты выступит ООО «ПроШкола» - структура, выступающая в рамках программы единым концессионером;

- выпуск инфраструктурных облигаций, поручителем по которым выступает ДОМ. РФ. В российской практике уже реализован проект стро- ительства загородного квартала «Белый хутор» в Челябинской области за счет инфраструктурных облигаций.

Таким образом, применение современного зарубежного опыта в российской практике государственно-частного партнерства позволит решить основные проблемы инфраструктурного развития государства.

\section{Зак^ючение}

Изучение российской и зарубежной практики государственно-частного партнерства позволило сформулировать современные тренды развития, заключающиеся в следующем:

- ориентация ГЧП на развитие устойчивой инфраструктуры, которой уделяется значительное внимание и в России и за рубежом, где больше всего проектов реализуется в энергетической и транспортной сфере. Так, в Канаде, проводятся программы по строительству пешеходных троп и мостов. Новыми инструментами финансирования устойчивой инфраструктуры выступают переходные, зеленые, социальные, голубые, устойчивые облигации, основное предназначение которых заключается в реализации проектов соответствующей направленности. Например, с помощью зеленых облигаций финансируются проекты с экологическими выгодами; голубые 
облигации - проекты по сохранению морей и океанов; социальные - проекты с социальными выгодами и т.д.;

- повышение качества городской инфраструктуры. Данный тренд включает в себя комплексное и устойчивое развитие городов; цифровизация городского хозяйства; трансформация городской социальной инфраструктуры. Для реализации данного тренда в зарубежных странах используются передовые подходы и технологии такие как: револьверные фонды; муниципальные облигации; краудфандинг и другие. С помощью инструмента инфраструктурного краудфандинга в Великобритании был создан городской парк Flyover в Ливерпуле. США револьверный фонд Clean Water State Revolving Fund используется для финансирования муниципальных проектов В водоснабжении. В российской практике уже есть примеры использования зарубежных методов к финансированию развитию городской инфраструктуры: проектов по утилизации ТKО; проекты социального воздействия (повышение образовательных результатов школьников в Республике Саха (Якутия);

- развитие цифровых платформ поддержки инфраструктуры, обеспечивающие процесс реализации ГЧП-проектов. Среди зарубежных платформ выделяются Global Infrastructure Pipeline, Source, национальная ГЧП - платформа Китая и другие. В России развивается платформа «РОСИНФРА», позволяющая осуществить поиск ГЧП-проектов; направлять проектные инициативы для рассмотрения. На базе платформы «РОСИНФРА» в 2021 году состоялся запуск цифрового проектного офиса - сервиса, обеспечивающего информационное взаимодействие стейкхолдеров по проектным инициативам в формате онлайн.

Таким образом, выявленные тренды подтверждают, что в России активно применяются передовые технологии зарубежных стран, что является безусловной поддержкой для дальнейшего развития инфраструктуры.

\section{ЛИТЕРАТУРА}

1. Агазарян, Н.В. Анализ мирового опыта применения механизма государственно-частного партнерства // Государственно-частное партнерство. 2016. № 2. C. 151-172.

2. Бабудоржиев, Б.Э. Взаимодействие государства, науки и бизнеса в условиях формирования инновационной экономики России // Тенденции развития экономики и менеджмента. 2016. С. 49-51.

3. Евченко, А.В. Исследование и регулирование регионального развития с использованием комплексных социально-экономических индикаторов. монография / А.В. Евченко; Кур. гос. техн. ун-т. Курск, 2004. 201 с.

4. Инвестиции в инфраструктуру ГЧП: аналитический обзор [Электронный ресурс]. - Режим доступа: https://rosinfra.ru/files/analytic/440/document/e6 1d39a50693cd9432bda434a8c13319.pdf (дата обращения 01.11.2021)

5. Каширцева, А.Ю. Упреждающее управление экономическими системами на основе имитационного моделирования / А.Ю. Каширцева, В.А. Дудко // Вестник Белгородского университета потребительской кооперации. 2009. № 4-1 (32). С. 143-150.

6. Матвеев, В.В. Инфраструктурное обеспечение государственной поддержки инновационного развития регионов / И.О. Нигоева, В.В. Матвеев // Экономические и гуманитарные науки. 2019. № 6 (329). С. 3-11.

7. Павлова, Л.Н. Государственное регулирование экономики: современные реалии и взгляд в будущее // Вестник Российского экономического университета имени Г.В. Плеханова. 2017. № 6 (96). С. 24-44.

8. Перепечаева, Е.С. Оценка и управление конкурентоспособностью промышленного предприятия / Е.С. Перепечаева, Е.С. Симоненко // Известия Юго-Западного государственного университета. 2012. № 5-2 (44). С. 298-306.

9. Плотников, В.А. Частно-государственное партнерство в организации профессионального образования в интересах российской промышленности / В.А. Плотников, Ю.В. Вертакова // Экономика и управление. 2012. № 11 (85). С. 36-40.

10. Фадюшин, И.С. Международный опыт развития ГЧП // Международный научно-исследовательский журнал. 2019. № . 4-2 (82). С. $39-43$.

11. Формы стратегического партнерства: модели взаимодействия в регионе / Вертакова Ю.В., Ватутина 0.0., Андросова И.В. и др. Курск: Изд-во ЮзГУ, 2013. 298 C.

12. Фирсова, А.А. Зарубежный опыт применения государственно-частных партнерств для развития инвестирования инновационной деятельности // Известия Саратовского университета. Новая серия. Серия Экономика. Управление. Право. 2011. Т. 11. № . 2. С. $75-76$

13. Шаповалова, Н.В. Государственно-частное партнерство: зарубежный опыт / Шаповалова Н.В., Королева Н.В. //Проблемы управления рыночной экономикой: межрегиональный сборник научных трудов. Томск, 2014. Ч. 1. С. 119-122. 